\title{
Modeling Viscosity of High Titania Slag
}

\author{
KAI HU, KAI TANG, XUEWEI LV, JAFAR SAFARIAN, ZHIMING YAN, \\ and BING SONG
}

$\mathrm{TiO}_{2}-\mathrm{FeO}-\mathrm{Ti}_{2} \mathrm{O}_{3}$ slag system is the dominant system for industrial high-titania slag production. In the present work, viscosities of $\mathrm{TiO}_{2}-\mathrm{FeO}$ and $\mathrm{TiO}_{2}-\mathrm{FeO}-\mathrm{Ti}_{2} \mathrm{O}_{3}$ systems were experimentally determined using the concentric rotating cylinder method under argon atmosphere. A viscosity model suitable for the $\mathrm{TiO}_{2}-\mathrm{FeO}-\mathrm{Ti}_{2} \mathrm{O}_{3}$ slag system was then established based on the modification of the Vogel-Fulcher-Tammann (VFT) equation. The experimental results indicate that completely melted high-titania slags exhibit very low viscosity of around $0.8 \mathrm{dPa}$ s with negligible dependence on temperature and compositions. However, it increases dramatically with decreasing temperature slightly below the critical temperature. Besides, the increase in $\mathrm{FeO}$ content was found to remarkably lower the critical temperature, while the addition of $\mathrm{Ti}_{2} \mathrm{O}_{3}$ increases it. The developed model can predict the viscosities of the $\mathrm{TiO}_{2}-\mathrm{FeO}-\mathrm{Ti}_{2} \mathrm{O}_{3}$ and $\mathrm{TiO}_{2}-\mathrm{FeO}$ systems over wide ranges of compositions and temperatures within experimental uncertainties. The average relative error for the present model calculation is $<18.82 \mathrm{pct}$, which is better than the previously developed models for silicate slags reported in the literature. An iso-viscosity distribution diagram was made for the $\mathrm{TiO}_{2}-\mathrm{FeO}-\mathrm{Ti}_{2} \mathrm{O}_{3}$ slag system, which can serve as a roadmap for the Ilmenite smelting reduction process as well as the high titania slags tapping process.

https://doi.org/10.1007/s11663-020-02002-8

(C) The Author(s) 2020

\section{INTRODUCTION}

ILMENITE smelting is a carbothermic reduction process to upgrade the mineral ilmenite $\left(\mathrm{FeTiO}_{3}\right)$ for subsequent $\mathrm{TiO}_{2}$ pigment production, yielding a $\mathrm{TiO}_{2}$-rich slag (generally, $\mathrm{TiO}_{2}>70$ mass pct) as the main product and pig iron as the by-product. The ilmenite smelting process using an electric submerge arc furnace (SAF) technology has already become a dominant process for producing high-titania slag worldwide ${ }^{[1]}$ During the smelting process, an inevitable problem is the sudden surges of a foamy high-titania slag, sometimes becoming uncontrollable and thereby prolonging the melting time. It is generally believed that this

KAI HU is with the College of Materials Science and Engineering, Chongqing University, Chongqing 400044, China and also with the Department of Materials Science and Engineering, Norwegian University of Science and Technology, 7049 Trondheim, Norway. KAI TANG is with SINTEF Industry, No-7465 Trondheim, Norway. Contact e-mail: Kai.Tang@sintef.no XUEWEI LV is with the College of Materials Science and Engineering, Chongqing University. Contact e-mail: lvxuewei@163.com JAFAR SAFARIAN is with the Department of Materials Science and Engineering, Norwegian University of Science and Technology. ZHIMING YAN is with the WMG, The University of Warwick. Coventry, CV47AL UK. BING SONG is with the Panzhihua Iron and Steel Research Institute, Panzhihua 617000, China.

Manuscript submitted June 18, 2020; accepted October 8, 2020.

Article published online November 4, 2020. foaming phenomenon is due mainly to the insufficient slag fluidity caused by changes in slag temperature or composition during the smelting process ${ }^{[2]}$ Furthermore, the fluidity of high-titania slag has a direct effect on the tapping behavior of the molten slag, the separation of the liquid slag and molten iron, and the SAF energy consumption. $^{[\beta]}$ Hence, relatively suitable viscosity of high-titania slag is the guarantee for the smooth operation and optimization of the SAF smelting process.

A preliminary literature survey indicated that very few publications deal with investigation of the viscosity of high-titania slag $\left(\mathrm{TiO}_{2}>70\right.$ mass pct). We even could not find any publications concerning the viscosity of high-titania slags before 1963. In the early studies, Russian investigators ${ }^{[4]}$ studied some synthetic $\mathrm{TiO}_{2}$-containing slag systems (18 to 92 mass pct $\mathrm{TiO}_{2}$ ) and concluded that completely molten synthetic titania slags exhibit low viscosities in the order of 1 to $3 \mathrm{dPa}$. However, more specific data were not released in their paper. Tuset ${ }^{[5]}$ reported the viscosity measurements of 54 different slags located in the $\mathrm{TiO}_{2}-\mathrm{Ti}_{2} \mathrm{O}_{3}-\mathrm{MgTiO}_{3}$ ternary system in 1968. He concluded that the completely molten slags are considerably fluid and have a low level of viscosity values, ranging from 0.5 to $1 \mathrm{dPa}$ s. Furthermore, he also claimed that, above the liquidus temperature, viscosities of the studied slags are almost independent of slag composition and temperature. Unfortunately, Tuset did not show any of his results 
on the measured viscosity data in tables or graphs. From 1971 to 1978 , Handfield and Charette ${ }^{[2]}$ published the viscosity of industrial high-titania slags (renowned as Sorel slag, which contains approximately 72 mass pct $\mathrm{TiO}_{2}$ ). Grau and Poggi ${ }^{[6]}$ investigated viscosity variation of the QIT slag with temperature [QIT slag was a high-titania slag $\left(\mathrm{TiO}_{2}>72\right.$ mass pct) produced by Quebec Titanium Iron Company (QIT), Canada]. These researchers obtained a consistent conclusion that high-titania slag exhibited a very low level of viscosity values stabilized at around $0.3 \mathrm{dPa}$ s. Besides, these values almost stayed constant with change in temperature and slag composition above the liquidus temperature. In 2009, Borowiec ${ }^{[7]}$ obtained almost identical conclusions for QMM slags (95 mass pet $\mathrm{TiO}_{2}$ ); however, only a set of viscosity data was published in his paper. Until recent years, several researchers have begun to study the viscosity of high-titania slags again. In our previous work, ${ }^{[3,8]}$ we measured viscosities of 24 different synthetic high $\mathrm{TiO}_{2}$ slags (45 to 88 mass pct $\mathrm{TiO}_{2}$ ) and reached some similar conclusions with the early studies mentioned above. ${ }^{[2,6,7]}$ However, our previous experimental viscosity values (around $0.65 \mathrm{dPa} s$ ) were slightly higher than those in the mentioned literature. Kim et $a l .^{[9]}$ experimentally measured the viscosity of $\mathrm{TiO}_{2}-\mathrm{FeO}$ binary slags and published three sets of similarly low level of viscosity data in their paper. Zhang et $a l .^{[10]}$ first conducted a thermodynamic simulation and then experimentally studied the viscosity of the $\mathrm{TiO}_{2}-\mathrm{FeO}-\mathrm{Ti}_{2} \mathrm{O}_{3}$ ternary slags. They also found that once completely melted, high titania slags displayed very low viscosity and were very insensitive to the temperature and slag compositions.

It is well known that the high-temperature viscosity measurement of metallurgical slags is time consuming and costly work because the high-titania slags have characteristics of high melting points (above $1650{ }^{\circ} \mathrm{C}$ ) and high reactivity as well as being corrosive toward all the ceramic containers. Thus, constructing an effective viscosity model to reproduce the viscosity of these slags is a important task. In the past decades, a wide variety of models has been proposed by researchers. ${ }^{[11-20]}$ However, most were developed to deal with molten silicate slags. When it comes to $\mathrm{TiO}_{2}$-bearing slags $\left(\mathrm{TiO}_{2}\right.$ $<40$ mass pct), only a few viscosity models ${ }^{[21,22]}$ are applicable. The viscosity models for high-titania slags $\left(\mathrm{TiO}_{2}>70\right.$ mass pct) have not been reported in the literature to date because high-titania slags are noticeably structurally different from the traditional polymerizing silicate slags ${ }^{[2]}$ and their high-temperature structure is still unknown to metallurgists. Thus, it is crucial to find a model that describes the temperature and composition dependence of the viscosity of high-titania slag by using a few adjustable parameters. ${ }^{[23]}$

In the present work, the viscosities of $\mathrm{TiO}_{2}-\mathrm{FeO}$ and $\mathrm{TiO}_{2}-\mathrm{FeO}-\mathrm{Ti}_{2} \mathrm{O}_{3}$ slags were measured experimentally using the rotating cylinder method under argon atmosphere. The present measurements together with our previous measurements as well as the literature data $^{[8-10,24]}$ were used to optimize the present viscosity model. This model was developed according to the modification of the Vogel ${ }^{[25]}-$ Fulcher $^{[26]}-$ Tammann $^{[27]}$
(VFT) semi-empirical formalism. The new viscosity model can describe the viscosities of the $\mathrm{TiO}_{2}-\mathrm{FeO}-$ $\mathrm{Ti}_{2} \mathrm{O}_{3}$ ternary high-titania slag system in broad composition and temperature ranges, including the solid-liquid slurries.

\section{EXPERIMENTAL AND DATASETS}

The chemical compositions of $\mathrm{TiO}_{2}-\mathrm{FeO}$ binary and $\mathrm{TiO}_{2}-\mathrm{FeO}-\mathrm{Ti}_{2} \mathrm{O}_{3}$ ternary slags used for viscosity measurement in this work are listed in Table I. Detailed information about the experimental procedure, apparatus, and sample preparation are given in our previous work. ${ }^{[3]}$ Viscosity measurements were carried out using a rotating cylinder viscometer in an airtight furnace with a ring-shaped graphite heater under argon atmosphere. Torque was measured by a Brookfield digital viscometer (model LVDV-II + Pro, Middleboro, MA). In our previous work, ${ }^{[3]}$ the pretreatment process of analytical grade reagents $\left(\mathrm{TiO}_{2}, \mathrm{FeO}\right.$, and $\left.\mathrm{Ti}_{2} \mathrm{O}_{3}\right)$ and preparation method of slag samples were described in detail. About $230 \mathrm{~g}$ pretreatment slag was charged in the molybdenum crucible, placed in the center of the ring-shaped graphite heater. The spindle was initially suspended $10 \mathrm{~mm}$ above the surface of the slag. The chamber of the furnace was evacuated to $20 \mathrm{~Pa}$ using a vacuum pump and then backfilled with high-purity argon (99.9999 pct) before the experiment. Repeating three times vacuum and argon blowing cycles, the residue oxygen in the furnace could be effectively eliminated to a very low level. Then, the furnace was heated to $2013 \mathrm{~K}$ and held for 2 hour to ensure the slag was completely molten and homogeneous. Subsequently, the spindle was carefully lowered toward the slag and aligned with the central axis of the crucible to reduce experimental error from slight deviations by the spindle. The dramatic change in measurements indicated the lower end of the spindle had just contacted the molten slag surface. Then, the spindle was further immersed $20 \mathrm{~mm}$ deep into the melts for the following viscosity measurements. This was performed from $2013 \mathrm{~K}$ to $1788 \mathrm{~K}\left(1740{ }^{\circ} \mathrm{C}\right.$ to $\left.1515^{\circ} \mathrm{C}\right)$ with equilibrium periods of 30 minute for every temperature point. The standard errors of viscosity were found to be $< \pm 0.02 \mathrm{dPa}$ s. To confirm the data reliability, multiple trials were performed.

All the available viscosity data are summarized in Table II. The issues related to the selection and acceptance of the experimental data for the optimization of the model parameters have been discussed in detail in the previous literature. ${ }^{[16,28]}$ In the present work, special attention was only focused on chemical compositions and temperature corresponding to the collected viscosity data. Therefore, the viscosity data with no specific compositions and temperature information were not considered in this work. It should be noted that the viscosity data published by $\mathrm{Li}$ et al. ${ }^{[8]}$ related to the $\mathrm{TiO}_{2}-\mathrm{FeO}-\mathrm{X}\left(\mathrm{CaO}, \mathrm{SiO}_{2}, \mathrm{MgO}\right)$ ternary slag system containing $\mathrm{CaO}$ (0.5 to 2 mass pet), $\mathrm{SiO}_{2}$ (2 to 6 mass pct), and $\mathrm{MgO}$ (1 to 4 mass pct), respectively. However, a small amount of $\left(\mathrm{CaO}, \mathrm{SiO}_{2}, \mathrm{MgO}\right)$ just had a slight influence on the viscosity compared to the $\mathrm{TiO}_{2}-\mathrm{FeO}$ 
Table I. Brief Summary of the Experimental Viscosity Data for the $\mathrm{TiO}_{2}$-Containing Slags

\begin{tabular}{|c|c|c|c|c|c|}
\hline System & References & Method & Crucible & Atmosphere & Number of Data \\
\hline \multirow[t]{3}{*}{$\mathrm{TiO}_{2}-\mathrm{FeO}$} & this work & rotating & Mo & argon & 39 \\
\hline & Kim et al. ${ }^{[9]}$ & rotating & Pt-10 pctRh & argon & 8 \\
\hline & Lopati et al. ${ }^{[24]}$ & Shvidkovski (OC) & Mo & helium & 10 \\
\hline \multirow{2}{*}{$\mathrm{TiO}_{2}-\mathrm{FeO}-\mathrm{Ti}_{2} \mathrm{O}_{3}$} & Zhang et al. ${ }^{[10]}$ & / & 1 & / & 92 \\
\hline & this work & rotating & Mo & argon & 38 \\
\hline $\mathrm{TiO}_{2}-\mathrm{FeO}-\mathrm{CaO}$ & Li et al..$^{[8]}$ & rotating & Mo & argon & 24 \\
\hline $\mathrm{TiO}_{2}-\mathrm{FeO}-\mathrm{SiO}_{2}$ & & & & argon & 32 \\
\hline $\mathrm{TiO}_{2}-\mathrm{FeO}-\mathrm{MgO}$ & & & & argon & 28 \\
\hline Total data & & & & & 271 \\
\hline
\end{tabular}

Table II. Chemical Composition of the Slags Studied in the Present Work

\begin{tabular}{|c|c|c|c|c|}
\hline \multirow[b]{2}{*}{ Slags } & \multicolumn{3}{|c|}{ Chemical Composition of the Designed Slags (Mass Pct) } & \multirow[b]{2}{*}{$\mathrm{Ti}^{4+} / \mathrm{Fe}^{2+}$} \\
\hline & $\mathrm{TiO}_{2}$ & $\mathrm{FeO}$ & $\mathrm{Ti}_{2} \mathrm{O}_{3}$ & \\
\hline 1 & 90.00 & 10.00 & 0 & 9.00 \\
\hline 2 & 85.00 & 15.00 & 0 & 5.67 \\
\hline 3 & 80.00 & 20.00 & 0 & 4.00 \\
\hline 4 & 75.00 & 25.00 & 0 & 3.00 \\
\hline 5 & 80.80 & 9.20 & 10.00 & 8.78 \\
\hline 6 & 79.00 & 9.00 & 12.00 & 8.78 \\
\hline 7 & 77.21 & 8.79 & 14.00 & 8.78 \\
\hline 8 & 75.41 & 8.59 & 16.00 & 8.78 \\
\hline
\end{tabular}

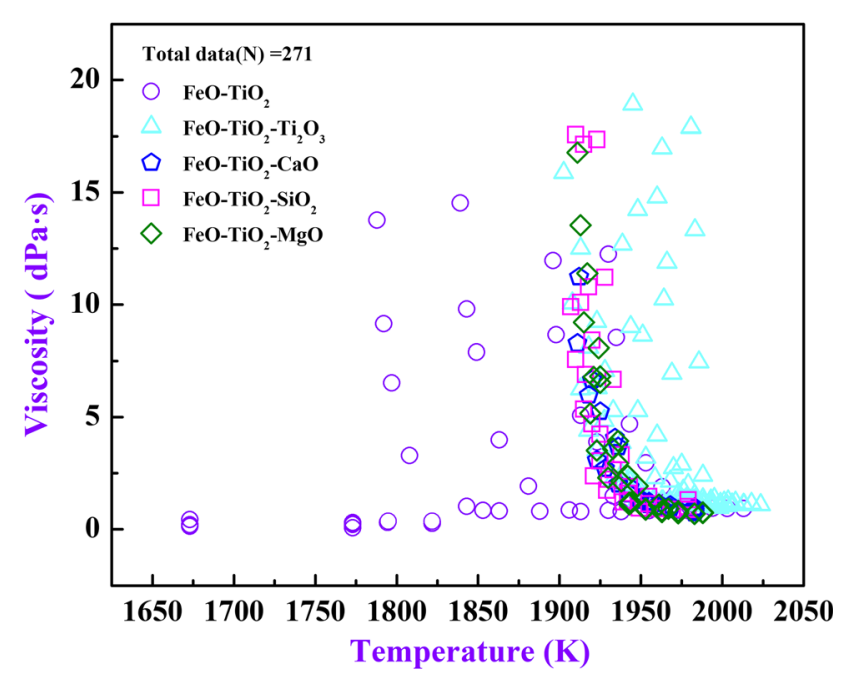

Fig. 1-Viscosity-temperature curve plotted from the viscosity data used in this work.

binary slag system in this work. Thus, the viscosity data of $\mathrm{TiO}_{2}-\mathrm{FeO}-\mathrm{X}\left(\mathrm{CaO}, \mathrm{SiO}_{2}, \mathrm{MgO}\right)$ ternary high-titania slag were also chosen as the basic data. Although these chosen viscosity data are different from each other, they are all of the same order of magnitude and not sensitive to slag compositions and temperatures above the liquidus temperature. In summary, about 271 data were used to calibrate the parameters of the present viscosity model. The range of viscosity values and temperature are shown in Figure 1. The viscosity data cover several orders of magnitude, from the binary to ternary system, and temperature in the range from $1663 \mathrm{~K}$ to $2020 \mathrm{~K}$.

\section{MODEL}

As mentioned above, no viscosity model suitable for high-titania slags exists. Thus, we focus on the famous VFT model, which is one of the most popular and extensive equations for the representation of the temperature dependence of viscosity. It has even been used by the National Institute of Standards and Technology to represent the viscosity of standard glasses. ${ }^{[29]}$ This model has also been regarded as an effective and classic descriptor of viscosity over a wide range of compositions and temperatures of most melts, most notably liquid oxides, and supercooled melts. ${ }^{[29]}$ The basic form of the VFT model can be written as follows ${ }^{[30]}$.

$$
\log _{10} \eta(T, x)=\log _{10} \eta_{\infty}(x)+\frac{A(x)}{T-T_{0}(x)}=A+\frac{B}{T-C}
$$

where $\eta$ is viscosity in $\mathrm{Pa} \mathrm{s}, T$ is the temperature in $\mathrm{K}$, $x$ is the composition (usually molar fraction). The three VFT parameters $\left(\eta_{\infty}, A\right.$, and $\left.T_{0}\right)$ are obtained by fitting Eq. [1] to the measured viscosity data. Generally, the adjustable parameters $A, B$, and $C$ are expected to depend on the compositions of slags. The 
parameter $A$ is the value of $\lg \eta(x)$ ( $\mathrm{Pa} \mathrm{s}$ ) at infinite high temperature, and $C$ denotes the temperature $(\mathrm{K})$ at which viscosity becomes infinite. The parameter $B$ corresponds to the pseudo-activation energy associated with the viscous flow and is thought to represent a potential energy barrier obstructing the structural rearrangement of the melt. ${ }^{[29,31]}$ The parameters of the original VFT equation (Eq. [1]) were related only to the slag compositions. However, this was not able to give an adequate description of the viscosity-composition-temperature relationships for high-titania slags by just taking the chemical compositions into account. The high-titania slags have strong crystallization characteristics and are very sensitive near the liquidus temperature. ${ }^{[8]}$ In this work, we consider parameters $B$ and $C$ are both composition- and temperature-dependent. Thus, the VFT model can be re-written here as follows:

$$
\lg \eta(T, x)=\lg \eta_{\infty}(x)+\frac{A(T, x)}{T-T_{0}(T, x)}=A+\frac{B}{T-C}
$$

It is generally accepted that the parameters of viscosity models could be fitted with multiple non-linear regression algorithms. ${ }^{[1-14,20]}$ In the present study, parameter A was just related to the compositions of the slag; parameters $\mathrm{B}$ and $\mathrm{C}$ were both related to the temperature by considering the linear relationship and slag compositions by simply considering the binary interactions between each component. Accordingly, the above parameters can be expressed as:

$$
\begin{gathered}
A=\lg \eta_{\infty}(x)=\sum_{i=1}^{n} r_{i} x_{i} \\
B=A(T, x)=\sum_{i=1}^{n} \sum_{j=1}^{m}\left[x_{i} x_{j}\left(a_{i j}+b_{i j} \cdot T\right)\right] \\
C=T_{0}(T, x)=\sum_{i=1}^{n} \sum_{j=1}^{m}\left[x_{i} x_{j}\left(c_{i j}+d_{i j} \cdot T\right)\right]
\end{gathered}
$$

here $\quad i \neq j, \quad a_{i j}=a_{j i}(b, c, d \quad$ same as $a)$, $b_{i i}=b_{j j}=d_{i i}=d_{j j}=0, x_{i}$ or $x_{j}$ is the molar fraction of component $i$ or $j$, and $r_{i}, a_{i j}, b_{i j}, c_{i j}, d_{i j}$ are the fitting parameters. All the model parameters were optimized by minimizing the least square of the errors given by
Eq. [6]. The optimization was carried out by the commercial Solver software using non-linear least-squares fitting based on the well-known Levenberg-Marquardt algorithm. ${ }^{[32,33]}$ A global constraint on the algorithm was also used to avoid local minima.

$$
\sum_{i=1}^{N}\left[\lg \eta_{\text {mea. }}-\left(\sum_{i=1}^{n} r_{i} x_{i}+\frac{\sum_{i=1}^{n} \sum_{j=1}^{m}\left[x_{i} x_{j}\left(a_{i j}+b_{i j} \cdot T\right)\right]}{T-\sum_{i=1}^{n} \sum_{j=1}^{m}\left[x_{i} x_{j}\left(c_{i j}+d_{i j} \cdot T\right)\right]}\right]\right]^{2}
$$

\section{RESULTS AND DISCUSSION}

\section{A. Viscosity-Temperature Curves of High-Titania Slags}

Figure 2 shows the measured viscosity of $\mathrm{TiO}_{2}-\mathrm{FeO}$ and $\mathrm{TiO}_{2}-\mathrm{FeO}-\mathrm{Ti}_{2} \mathrm{O}_{3}$ slags as a function of temperature in this work. All the slags had the characteristic of "short slag" (this is a term used by the metallurgists, which represents the viscosity of slag/slurry increase sharply after the temperature drops from the "critical point"). Besides, the changing trends of the viscosity are almost identical to each other, that is, the viscosity of the slags is expected to increase with decreasing temperatures. Viscosity-temperature curves can generally be divided into three parts: the fully molten region (Newtonian flow), solid-liquid coexistence region (transient flow), and solidification region (non-Newtonian flow). Consequently, the effect of crystallization behavior on the viscosity of high-titania slags can be schematically shown in Figure 3. The change of the viscosity of the studied slags with temperature corresponding to the variation of the crystalline precipitation phase is discussed in detail below.

Above the liquidus temperature, all the high-titania slags exhibit a low viscosity of approximately $0.8 \mathrm{dPa} \mathrm{s}$, with almost negligible dependence on temperature and compositions. Similar results and trends of viscosity-temperature relationships were also found in other literature. ${ }^{[2,3,34]}$ The appearance of the lowest viscosity level may clearly imply the absence of any appreciable proportion of large, directional-bonded polymerized ions in this melt compared with silicate slag. The remarkable difference in behavior is likely caused by the different structures of the slags. Silicate slags exhibit higher viscosities because of the higher polymerization (of $\mathrm{SiO}_{4}^{4-}$ tetrahedra) in their molten state, being 1.6 to 


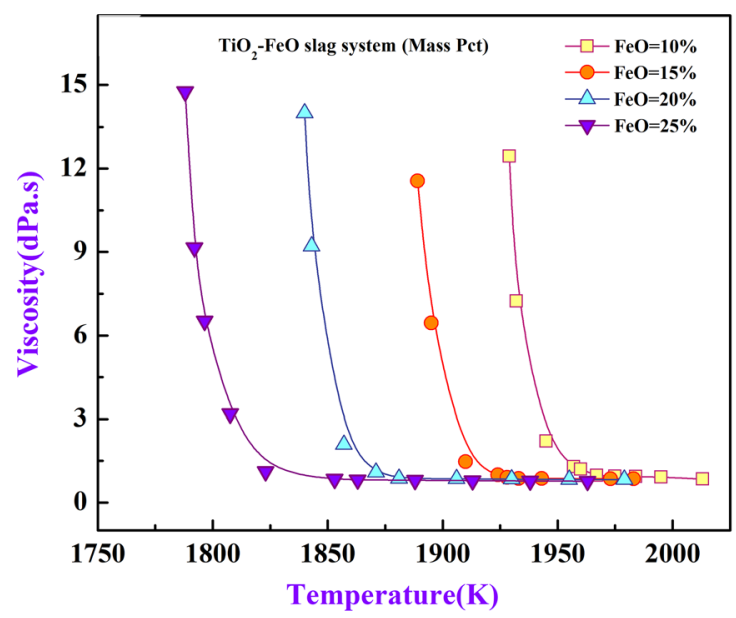

(a)

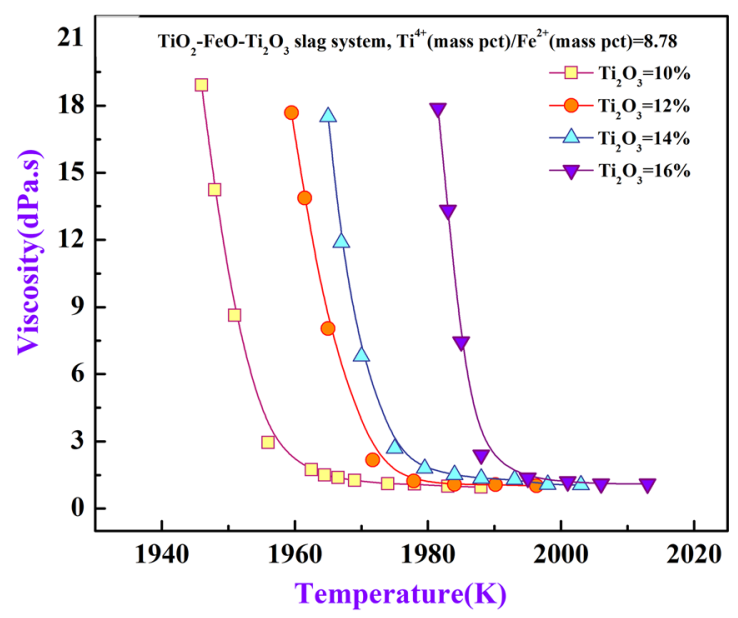

(b)

Fig. 2-Viscosity of (a) $\mathrm{TiO}_{2}-\mathrm{FeO}$ and (b) $\mathrm{TiO}_{2}-\mathrm{FeO}-\mathrm{Ti}_{2} \mathrm{O}_{3}$ systems with temperature.

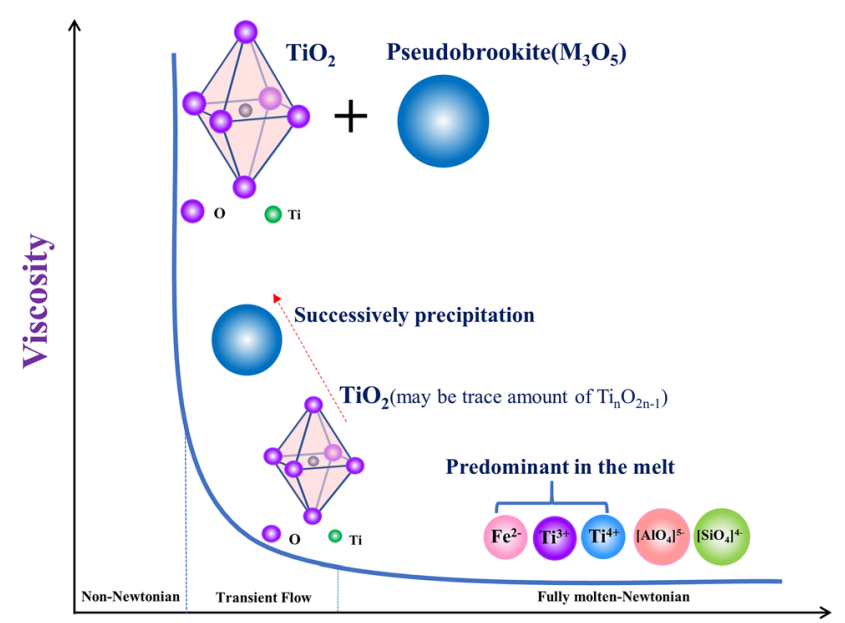

Temperature

Fig. 3-Illustration of the influence of crystallization on the viscosity of high-titania slags.

$56 \mathrm{dPa} \mathrm{s},{ }^{[22]}$ whereas high-titania slags are prone to crystalline configurations from simple ions during the cooling process. Pesl et al. ${ }^{[35]}$ presumed that, above liquidus temperature, high-titania slags are dissociated into simple ions like $\mathrm{Ti}^{4+}, \mathrm{Ti}^{3+}$, and $\mathrm{Fe}^{2+}$ and therefore have no network structure like the silicate slags, resulting in the very low viscosity of molten slags.

As the temperature decreased to the turning point of the viscosity-temperature curve, all slags manifested a sharp increase in viscosity during cooling. Obviously, the sharp increase of viscosity is due mainly to the appearance of the crystalline precipitations. It should be noted that a very narrow crystalline region appeared in the vicinity of the turning point where the crystalline precipitations began to precipitate successively from the molten slag. Actually, Pistorius et al. ${ }^{[34,36]}$ and our early investigation ${ }^{[37]}$ have clearly elaborated that the rutile $\left(\mathrm{TiO}_{2}\right)$ and pseudobrookite begin to precipitate successively from the molten high-titania slag when the temperatures dropped to the critical temperature (liquidus temperature), which referred to a transition from a fully molten state to a partially crystalline state. It should be emphasized that the turning point temperature in the viscosity-temperature curves were called the critical temperature in our previous work. ${ }^{[3]}$ Both represent the liquidus temperature of the slags. Furthermore, $\mathrm{FeO}$ had a strong fluxing effect, which could remarkably lower the critical temperature, whereas $\mathrm{Ti}_{2} \mathrm{O}_{3}$ addition significantly increased the critical temperature, as shown in Figures 2(a) and (b). The critical temperature marked the boundary between crystal precipitation and non-crystal precipitation corresponding to the Newtonian and non-Newtonian liquid behavior of high titania slag. ${ }^{[38]}$ This is the most intriguing feature of the viscosity-temperature curve of the high-titania slags because the so-called critical temperature restricts the minimum smelting temperature for the ilmenite smelting process.

At temperatures below the critical temperature, the viscosity increased sharply with decreasing temperature and was close to infinite when complete solidification of the slag occurred. Here, the high-titania slag can be viewed as a solution conforming to a dominant phase pseudobrookite $\left(\mathrm{M}_{3} \mathrm{O}_{5}\right)$ and minor phase rutile $\left(\mathrm{TiO}_{2}\right)$. This can be supported by the tendency of high-titania slags to conform to $\mathrm{M}_{3} \mathrm{O}_{5}$ stoichiometry in equilibrium cooling and solidification. ${ }^{[34,39]}$

\section{B. Model Validation}

The performance of the current model on viscosity prediction was evaluated by calculating the average relative errors $\Delta$, which is expressed as the following equation.

$$
\Delta=\frac{1}{N} \sum_{i=1}^{N} \frac{\left|\eta_{i, \text { meas. }}-\eta_{i, \text { est. }}\right|}{\eta_{i, \text { meas. }}} \times 100 \text { Pct }
$$


Table III. Optimized Parameter Values Used for the Current Model

\begin{tabular}{lcccccc}
\hline$r_{1}$ & $r_{2}$ & $r_{3}$ & $a_{11}$ & $a_{12} / 10^{10}$ & $a_{13} / 10^{10}$ & $a_{22}$ \\
\hline-0.2728 & -0.7498 & -0.6505 & -66718.9591 & $25,394.3301$ & 46.8047 & 3424.4811 \\
\hline \hline$a_{23}$ & $a_{33}$ & $b_{12}$ & $b_{13} / 10^{10}$ & $b_{23}$ & $c_{11}$ & $c_{12} / 10^{10}$ \\
\hline 23.4110 & $4,715,330.3858$ & -674.3252 & -11.1258 & $78,122,740.1248$ & $873,479.3818$ & -2005759.2910 \\
\hline \hline$c_{13 / 10^{10}}$ & $c_{22} / 10^{10}$ & $c_{23} / 10^{10}$ & $c_{33}$ & $d_{12} / 10^{10}$ & $d_{13} / 10^{10}$ & $d_{23}$ \\
\hline $123,341.0237$ & $572,019.6821$ & -354228.7293 & -28876781.5182 & 1011.9653 & -637.1605 & 386.9354 \\
\hline
\end{tabular}

Here, $\eta_{i \text {,meas. }}$ and $\eta_{i, \text { est. }}$ are the measured and estimated viscosity values, respectively. $N$ is the number of viscosity data points. The optimized model parameter values are listed in Table III.

A comparison between the experimental data and calculated results of binary and ternary high-titania slags for all the 271 collected viscosity data is shown in Figure 4 . There is good agreement between the experimental data and the model-calculated results, with overall accuracy of 18.82 pct. The current viscosity model for high-titania slags is more accurate than the early viscosity models ${ }^{[16,40,41]}$ for silicate slags (the relative error is $>20 \mathrm{pct}$ ). The relative errors of each slag system studied in this work are summarized in Figure 5. Evidently, the present model could also exhibit a satisfactory accuracy for most slag systems with a relative error $<20$ pct except for the $\mathrm{TiO}_{2}-\mathrm{FeO}-\mathrm{SiO}_{2}$ slag system. Thus, application of the developed model can be attempted to assist in the solution of various practical issues during the industrial titanium slag smelting process.

\section{Application of the Model for High-Titania Slags}

\section{1. $\mathrm{TiO}_{2}-\mathrm{FeO}$ binary system}

The $\mathrm{TiO}_{2}-\mathrm{FeO}$ slag system is a major component of ilmenite ore, which is widely used to yield $\mathrm{TiO}_{2}$-rich slag during the ilmenite smelting process. The experimental viscosity data for the $\mathrm{TiO}_{2}-\mathrm{FeO}$ system are available from Kim et al., ${ }^{[9]}$ Lopatin et al., ${ }^{[2]}$ and this work. Lopatin et al. ${ }^{[24]}$ used a molybdenum crucible under helium atmosphere. They claimed that the slag composition may contain little $\mathrm{Fe}_{2} \mathrm{O}_{3}$. Kim et al. ${ }^{[9]}$ reported some viscosity data above the liquidus temperature. But the specific experimental conditions and apparatus were not mentioned. The predicted viscosity dependence on the temperature for different compositions in the $\mathrm{TiO}_{2}-\mathrm{FeO}$ system was compared with experimental results in Figures 6 and 7(a) and (b), respectively. Obviously, the current model exhibited better performance for predicting the viscosity data by this work (Figure 6) both above and below the liquidus temperature. Furthermore, an appreciable increase in the model-predicted viscosity occurred with the increase of $\mathrm{TiO}_{2}$ content, showing good agreement with the experimental results (Figure 7). Data by Lopatin et al. ${ }^{[24]}$ showed some discrepancies with the current model at low temperatures (Figure 7(a)). However, they agree well with each other at high temperature. Our calculated viscosities are slightly higher than the viscosity data reported by Lopatin et al. ${ }^{[24]}$ This might be because most of the collected viscosity data were

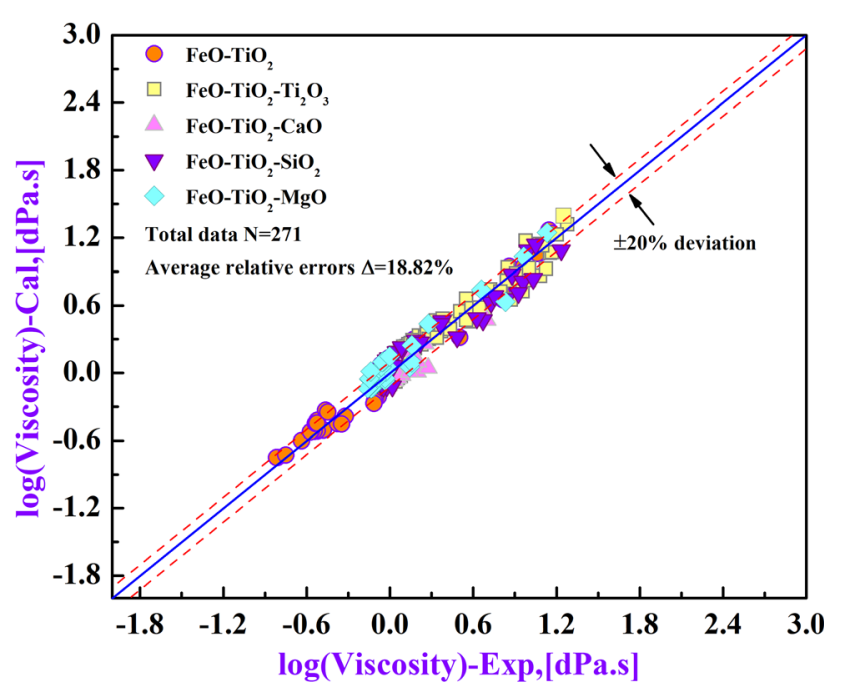

Fig. 4-Comparison between the experimental and estimated viscosity of the entire slag system.

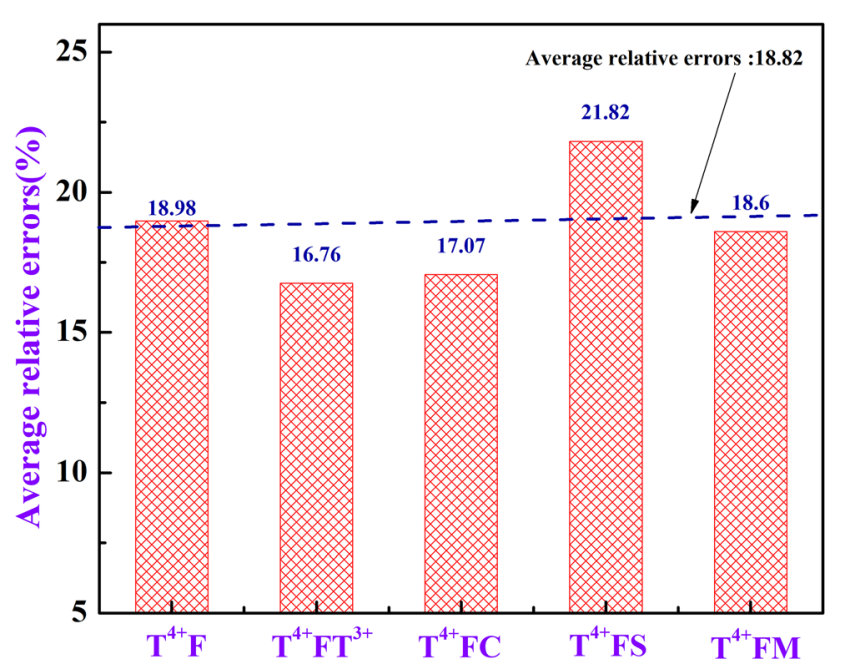

Fig. 5-Estimated performance of the present model for each system studied in this work $\left(\mathrm{T}^{4+}, \mathrm{F}, \mathrm{T}^{3+}, \mathrm{C}, \mathrm{S}\right.$, and $\mathrm{M}$ represent $\mathrm{TiO}_{2}$, $\mathrm{FeO}, \mathrm{Ti}_{2} \mathrm{O}_{3}, \mathrm{CaO}, \mathrm{SiO}_{2}$, and $\mathrm{MgO}$, respectively).

located in the relatively higher value region compared with Lopatin et al.'s results. For better predictive performance, more experimental data are needed to evaluate the model more precisely in the future. 
A comparison of the calculated and measured viscosities in the $\mathrm{TiO}_{2}-\mathrm{FeO}$ slag system is shown in Figure 8. Most of the experimental data were reproduced well by the present model, with an accuracy of 18.98 pet.

\section{2. $\mathrm{TiO}_{2}-\mathrm{FeO}-\mathrm{Ti}_{2} \mathrm{O}_{3}$ ternary system}

The $\mathrm{TiO}_{2}-\mathrm{FeO}-\mathrm{Ti}_{2} \mathrm{O}_{3}$ slag system is the dominant component in industrial high-titania slag. $\mathrm{SiO}_{2}$ is a minor impurity together with $\mathrm{CaO}$ and $\mathrm{MgO}$. Figure 9 shows the model-calculated viscosities compared with the measured viscosities for the $\mathrm{TiO}_{2}-\mathrm{FeO}-\mathrm{Ti}_{2} \mathrm{O}_{3}(\mathrm{CaO}$, $\mathrm{SiO}_{2}, \mathrm{MgO}$ ) slag system, respectively. During the ilmenite smelting process, there is a complex adhering slag layer containing liquid, partially crystalline, or even solidified phase depending on the temperature and compositions between the liquid high-titania slag and

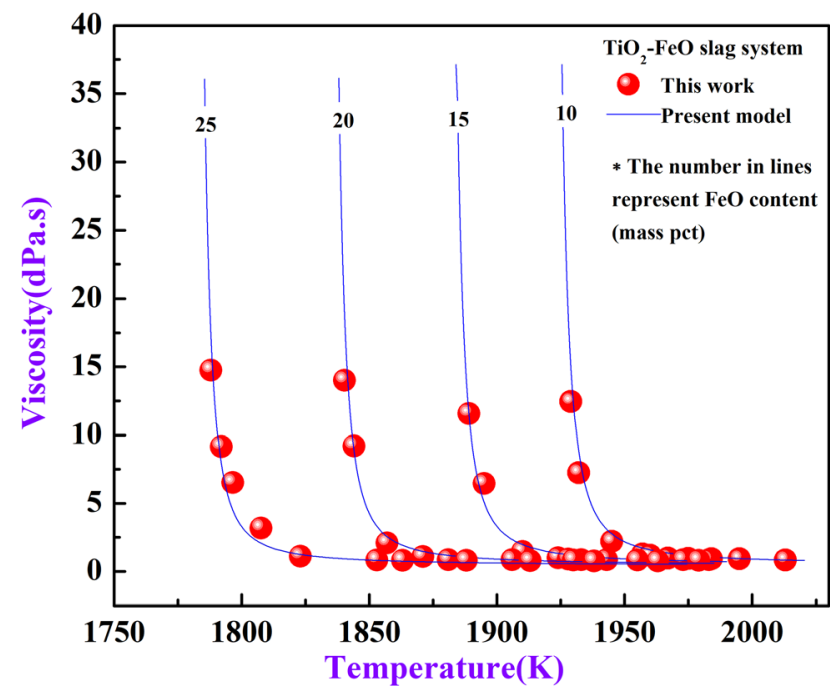

Fig. 6-Predicted viscosity dependent on temperature in the $\mathrm{TiO}_{2}-\mathrm{FeO}$ system compared with the experimental results. refractory inner wall. The slag layer can protect the refractory materials from highly corrosive high-titania slags. An appropriate viscous flow must be maintained to ensure the smooth operation of the adhering slag and also to prevent blockage of the slag tap, which may lead to an unscheduled shutdown of the electric arc furnace.

Except for the experimentally determined viscosity for the ternary $\mathrm{TiO}_{2}-\mathrm{FeO}-\mathrm{Ti}_{2} \mathrm{O}_{3}$ system, only Zhang et al. ${ }^{[10]}$ reported viscosity data for this ternary system in the literature. In the present work, viscosity measurements were performed in a customized vacuum high-temperature furnace (maximum temperature: $1800{ }^{\circ} \mathrm{C}$ ) under argon atmosphere, and a Mo crucible was used as the slag container, as mentioned in our previous work. ${ }^{[3]}$ Zhang et al. ${ }^{[10]}$ obtained viscosity data by FactSage calculation based on the Einstein-Roscoe equation and also took experimental measurements from the liquidus

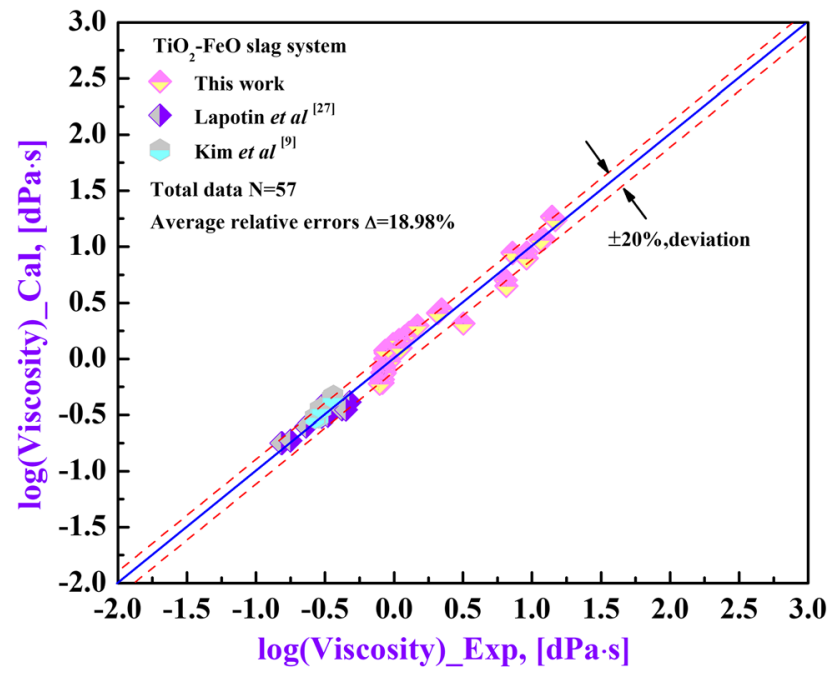

Fig. 8 - Comparison between predicted and experimental viscosities for the $\mathrm{TiO}_{2}-\mathrm{FeO}$ system.

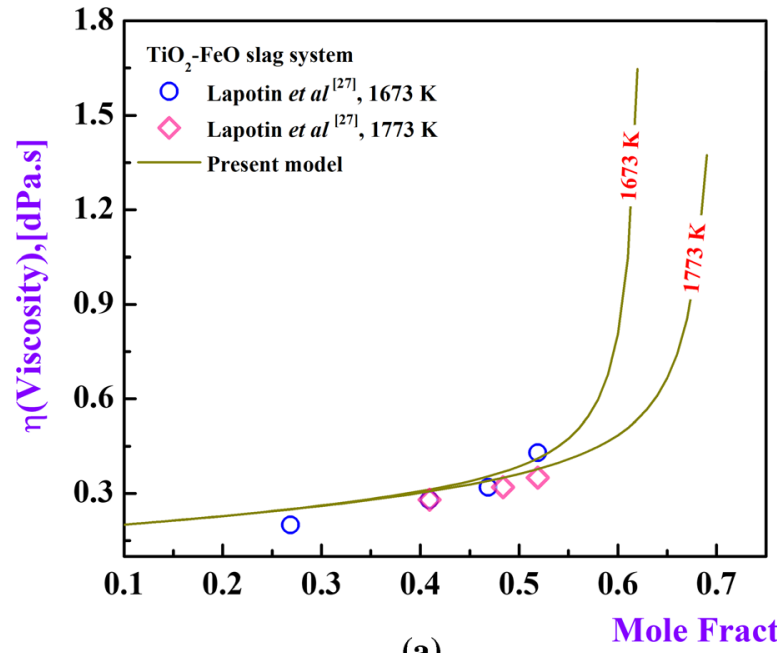

(a)

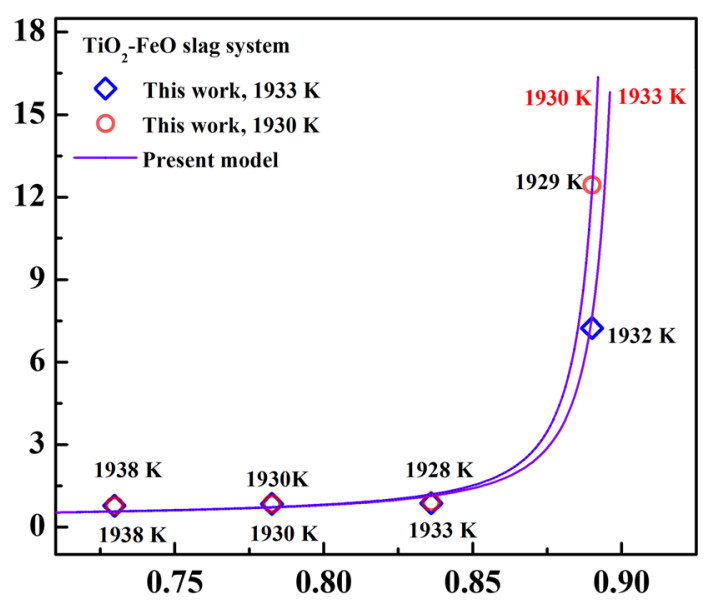

(b)

Fig. 7-Predicted viscosity dependence on the slag composition in the $\mathrm{TiO}_{2}-\mathrm{FeO}$ system at different temperatures compared with $(a)$ the literature ${ }^{[24]}$ and $(b)$ this work. 


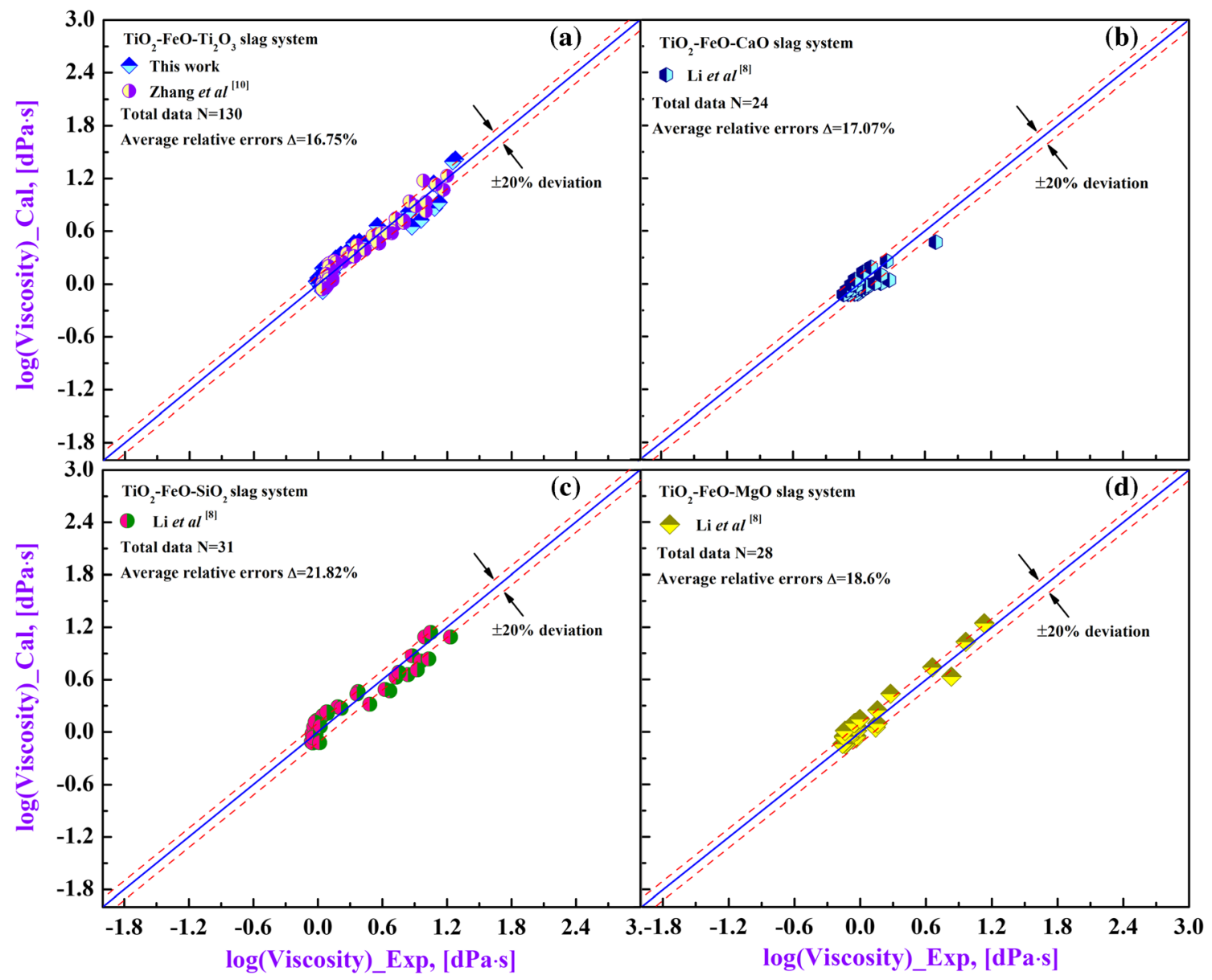

Fig. 9 - Comparison between model-calculated and experimentally measured viscosity for each slag system: $(a) \mathrm{TiO}_{2}-\mathrm{FeO}_{-} \mathrm{Ti}_{2} \mathrm{O}_{3}$ system; $(b)$ $\mathrm{TiO}_{2}-\mathrm{FeO}-\mathrm{CaO}$ system; (c) $\mathrm{TiO}_{2}-\mathrm{FeO}-\mathrm{SiO}_{2}$ system; (d) $\mathrm{TiO}_{2}-\mathrm{FeO}-\mathrm{MgO}$ system.

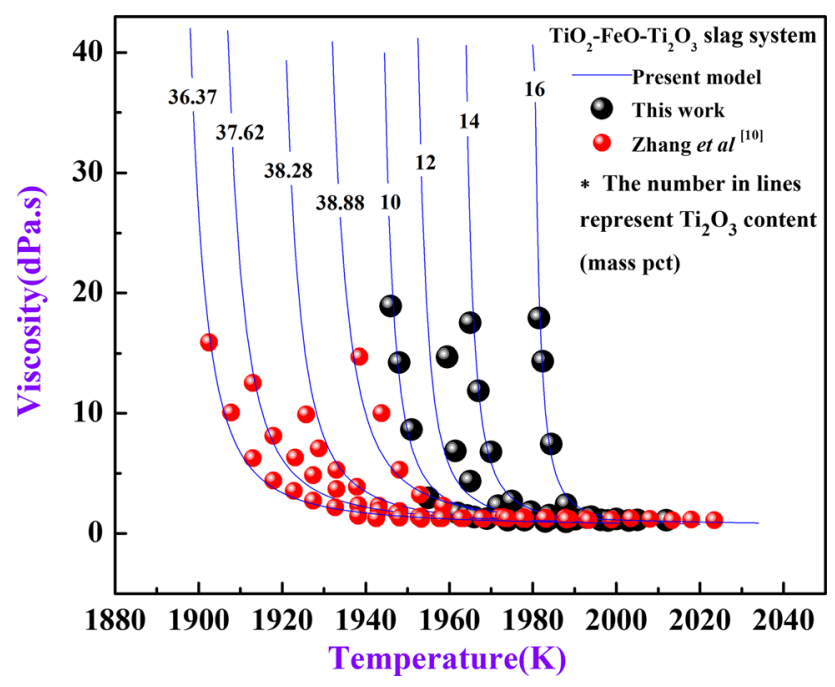

Fig. 10-Comparison between the predicted and experimental viscosities for the $\mathrm{TiO}_{2}-\mathrm{FeO}-\mathrm{Ti}_{2} \mathrm{O}_{3}$ system.

temperature to sub-liquidus temperature, but the experimental details were not published. Figure 10 shows the temperature dependence on the calculated viscosities in

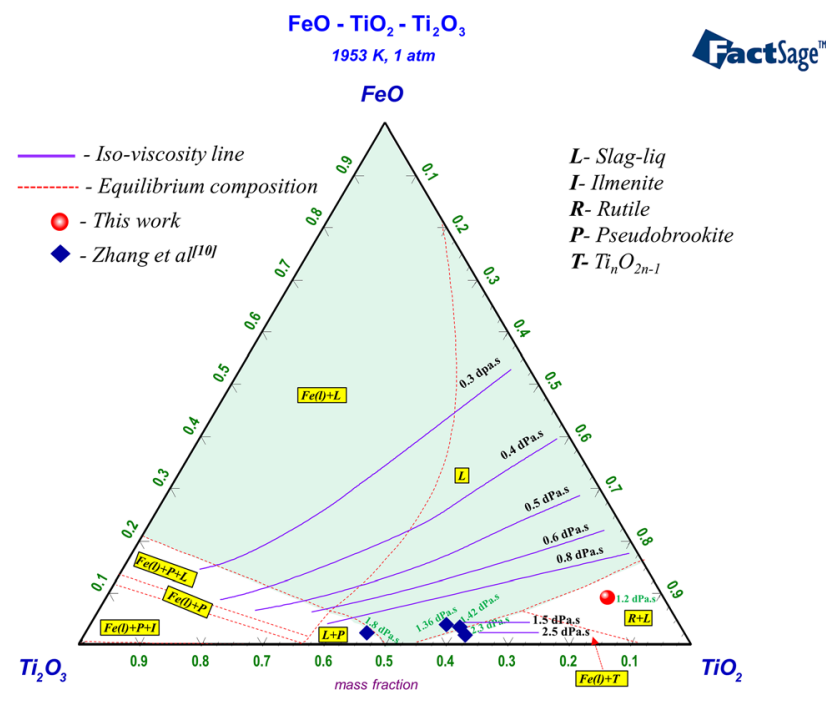

Fig. 11-Predicted iso-viscosity curves for the $\mathrm{TiO}_{2}-\mathrm{FeO}-\mathrm{Ti}_{2} \mathrm{O}_{3}$ system at $1953 \mathrm{~K}$ compared with selected literature.

the $\mathrm{TiO}_{2}-\mathrm{FeO}-\mathrm{Ti}_{2} \mathrm{O}_{3}$ system by the present model. The experimental data in the literature ${ }^{[10]}$ and this work are also superimposed. Most of the experimental data show 
good agreement with the current model at the low-viscosity range, but small differences exist at the high-viscosity domain. The graph in Figure 9(a) shows an average relative error of 16.57 pct was obtained for these slags.

Generally, the smelting temperature is in the approximate range from $1873 \mathrm{~K}$ to $2073 \mathrm{~K}\left(1600{ }^{\circ} \mathrm{C}\right.$ to $\left.1800{ }^{\circ} \mathrm{C}\right)$ during the ilmenite smelting process. Figure 11 depicts the model-calculated iso-viscosity curves in the $\mathrm{TiO}_{2-}$ $\mathrm{FeO}-\mathrm{Ti}_{2} \mathrm{O}_{3}$ slag system at $1680^{\circ} \mathrm{C}$; experimental data were also superimposed. It was evident that the present model reproduced the viscosities for the system adequately. The light green shaded region represents the isothermal liquidus section of the $\mathrm{TiO}_{2}-\mathrm{FeO}-\mathrm{Ti}_{2} \mathrm{O}_{3}$ slag system at $1953 \mathrm{~K}\left(1680{ }^{\circ} \mathrm{C}\right)$, which was calculated using FactSage7.2 software with the phase module. The isothermal liquidus section consists of two parts, the liquid slag phase region and two coexisting liquid phase regions [liquid slag phase and liquid iron phase $\mathrm{Fe}(l)$ ]. The appearance of liquid $\mathrm{Fe}$ phase defined the oxygen potential of the system to establish a steady state or approach an equilibrium state since the forms of $\mathrm{Ti}$ oxides strongly depend upon the oxygen potential. Each solid line characterizes the distribution of a certain viscosity value corresponding to the slag compositions. The red dashed lines represent the equilibrium slag composition. The viscosity increased with increasing titanium oxide content, whereas $\mathrm{FeO}$ exerted a strong fluxing effect on the slag, which agreed well with our previous work. ${ }^{[3]}$ Such diagrams can be used as a "roadmap" for the smelting metallurgist to understand and control the smelting process and tap high-titania slags during industrial production.

\section{CONCLUSIONS}

The viscosity of the $\mathrm{TiO}_{2}-\mathrm{FeO}$ binary and $\mathrm{TiO}_{2}-\mathrm{FeO}-$ $\mathrm{Ti}_{2} \mathrm{O}_{3}$ ternary system was measured experimentally. A viscosity model, based on modification of the VFT equation, has been developed for the $\mathrm{TiO}_{2}-\mathrm{FeO}-\mathrm{Ti}_{2} \mathrm{O}_{3}$ ternary high titania slag system. The main conclusions are summarized as follows:

(1) Once completely molten, high titania slags exhibit a very low viscosity of around $0.8 \mathrm{dPa}$ s. This viscosity shows a negligible dependence on the temperature and slag compositions even with a further increase in temperature.

(2) $\mathrm{FeO}$ exerts a fluxing effect on lowering the critical temperature, in contrast with the effects of $\mathrm{Ti}_{2} \mathrm{O}_{3}$.

(3) The current model is capable of predicting the viscosities of the $\mathrm{TiO}_{2}-\mathrm{FeO}-\mathrm{Ti}_{2} \mathrm{O}_{3}$ system over wide ranges of composition $\left(\mathrm{TiO}_{2}\right.$ : 0.598 to 0.890 mole fraction, FeO: 0.027 to 0.954 mole fraction, $\mathrm{Ti}_{2} \mathrm{O}_{3}$ : 0.058 to 0.375 mole fraction) and temperature (1663 $\mathrm{K}$ to $2020 \mathrm{~K}$ ). The average relative error for this model is 18.82 pct.

(4) Based on the model, the iso-viscosity distribution diagram was established for high titania slag, which can serve as a roadmap for the ilmenite smelting reduction as well as the high titania slag tapping process.

\section{ACKNOWLEDGMENTS}

We thank SFI Metal Production, Norwegian Research Centre for Research-Based Innovation (No. 237738) for supporting this research work. The authors are especially grateful to the China Scholarship Council's (CSC) oversea study for funding support. The authors are also pleased to acknowledge the financial support provided by the National Key R\&D Program of China (No. 2018YFC1900500) and project supported by the Graduate Scientific Research and Innovation Foundation of Chongqing, China (Grant No. CYB19001).

\section{FUNDING}

Open Access funding provided by SINTEF AS.

\section{OPEN ACCESS}

This article is licensed under a Creative Commons Attribution 4.0 International License, which permits use, sharing, adaptation, distribution and reproduction in any medium or format, as long as you give appropriate credit to the original author(s) and the source, provide a link to the Creative Commons licence, and indicate if changes were made. The images or other third party material in this article are included in the article's Creative Commons licence, unless indicated otherwise in a credit line to the material. If material is not included in the article's Creative Commons licence and your intended use is not permitted by statutory regulation or exceeds the permitted use, you will need to obtain permission directly from the copyright holder. To view a copy of this licence, visit http://creativec ommons.org/licenses/by/4.0/.

\section{REFERENCES}

1. D.M. Glen, A.F. Schoukens. Production of High Titania Slag from Ilmenite. CA, 1993.

2. G. Handfield and G.G. Charette: Can. Metall. Q., 1971, vol. 10, pp. 235-43.

3. K. Hu, X.W. Lv, S.P. Li, W. Lv, B. Song, and K. Han: Metall. Mater. Trans. B, 2018, vol. 49B, pp. 1963-73.

4. V.A. Reznichenko, M.B. Rapoport, and V.A. Tkachenko: The Metallurgy of Titanium: Investigation of Electric Melting of Titanium Slags (English translation), U.S. Dept. Commerce, Washington, 1963.

5. J.K. Tuset: Tidsskrift for Kjemi Berfvesenog Metallurgi, 1968, vol. 28 , pp. $232-40$

6. A. Grau and D. Poggi: Can. Inst. Min. Metall., 1978, vol. 17, pp. $97-102$.

7. K. Borowiec. Proceedings of the VIII International, Conference on Molten Slags, Fluxes and Salts, Santiago, Chile, 2009, pp. 18-21.

8. S.P. Li, X.W. Lü, B. Song, H.J. Miao, and K.X. Han: Trans. Nonferr. Met. Soc. China, 2016, vol. 26, pp. 2015-22.

9. Y. Kim and H. Park: Sci. Rep., 2019, vol. 9, pp. 1-12.

10. P. Zhang, W.H. Ma, S.J. Zhang, Y. Lei, and J. Wen: Trans. Nonferr. Met. Soc. China, 2018, vol. 28, pp. 1876-82.

11. G. Urbain: Steel Res. Int., 1987, vol. 58, pp. 111-16.

12. G. Urbain, F. Cambier, M. Deletter, and M.R. Anseau: Trans. J. Br. Ceram. Soc., 1981, vol. 80, pp. 139-41. 
13. P.V. Riboud, Y. Roux, L.D. Lucas, and H. Gaye: Fachber. Huttenpraxis Metallweiterverarb, 1981, vol. 19, pp. 859-69.

14. K.C. Mills and S. Sridhar: Ironmak. Steelmak., 1999, vol. 26 , pp. $262-68$.

15. H. Hu and R.G. Reddy: High Temp. Sci., 1988, vol. 28, pp. 195 202.

16. M. Suzuki and E. Jak: Metall. Mater. Trans. B, 2013, vol. 44B, pp. 1451-65.

17. M. Suzuki and E. Jak: ISIJ Int., 2014, vol. 54, pp. 2134-43.

18. G.H. Zhang and K.C. Chou: Steel Res. Int., 2013, vol. 84, pp. 63137.

19. G.H. Zhang, K.C. Chou, and K. Mills: Metall. Mater. Trans. B, 2014, vol. 45B, pp. 698-704.

20. T. Iida, H. Sakai, Y. Kita, and K. Shigeno: ISIJ Int., 2000, vol. 40, pp. S110-14.

21. Z.M. Yan, R.G. Reddy, X.W. Lv, Z.D. Pang, and W.C. He: Ironmak. Steelmak., 2018, vol. 47 (2), pp. 203-09.

22. X. J. Dong, H.Y. Sun, X. F. She, Q. G. Xue, J. S Wang. Ironmak. Steelmak., vol. 41, pp. 99-106.

23. V.K.G. Sturm: Glastechn Ber, 1980, vol. 53, pp. 63-76.

24. V.M. Lopatin, Y.P. Nikitin, L.N. Barmin, and I.B. Bobylev: Fiz. Khim. Issled. Metall. Protsessov, 1975, vol. 3, pp. 63-66.

25. H. Vogel: Phys. Z., 1921, vol. 22, pp. 645-46.

26. G.S. Fulcher: J. Am. Ceram. Soc., 1925, vol. 8, pp. 339-55.

27. G. Tammann and W.Z. Hesse Hesse: Allg. Chem, 1926, vol. 156, pp. $245-57$.

28. A. Kondratiev and E. Jak: Metall. Mater. Trans. B, 2001, vol. 32B, pp. 1015-25.
29. Q.J. Zheng and J.C. Mauro: J. Am. Ceram. Soc., 2017, vol. 100, pp. 6-25.

30. J.C. Maur, Y.Z. Yue, A.J. Ellison, P.K. Gupta, and D.C. Allan: PNAS., 2009, vol. 106, pp. 19780-84.

31. J.K. Russell, D. Giordano, and D.B. Dingwell: Am. Mineral., 2003, vol. 88, pp. 1390-94.

32. M.I. Lourakis: Found. Res. Technol., 2005, vol. 4, pp. 1-6.

33. L.S. Ngia and J. Sjoberg: IEEE Trans. Signal Process, 2000, vol. 48, pp. 1915-27.

34. P.C. Pistorius and C. Coetzee: Metall. Mater. Trans. B, 2003, vol. 34B, pp. 581-88.

35. J. Pesl and R.H. Eriç: Metall. Mater. Trans. B, 1999, vol. 30B, pp. 695-705.

36. P.C. Pistorius: J. South Afr. Inst. Min. Metall., 1999, vol. 108, pp. $35-43$.

37. K. Hu, X.W. Lv, W.Z. Yu, Z.M. Yan, W. Lv, and S.P. Li: Metall. Mater. Trans. B, 2019, vol. 50B, pp. 2982-92.

38. S. Seebold, G. Wu, and M. Müller: Fuel, 2017, vol. 187, pp. 37687.

39. J. Heimo, A. Jokilaakso, M. Kekkonen, M. Tangstad, and A. Støre: Metall. Res. Technol., 2019, vol. 116, pp. 1-10.

40. L. Gan and C. Lai: Metall. Mater. Trans. B, 2014, vol. 45B, pp. $875-88$.

41. C. Han, M. Chen, W. Zhang, Z. Zhao, T. Evans, and B. Zhao: Metall. Mater. Trans. B, 2016, vol. 47B, pp. 2861-74.

Publisher's Note Springer Nature remains neutral with regard to jurisdictional claims in published maps and institutional affiliations. 